\title{
The role of the public health system in improving health indicators of population
}

\section{Department of Health Policy and Management, Al- Farabi Kazakh National University, Almaty, Republic of Kazakhstan}

Yerlan Kiyassov, Gulya Sarybaeva, Togzhan Khaidarova

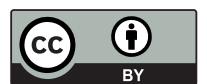

This work is licensed under a Creative Commons Attribution 4.0 International License

Received: 2018-04-27

Accepted: 2018-04-30

UDC: 616.1

J Clin Med Kaz 2018;2(48):59-62

Corresponding Author: Y. Kiyassov, Department

of Health Policy and Management, Al-Farabi

Kazakh National University, Almaty, Republic of

Kazakhstan.

E-mail: erlandez@inbox.ru Affairs Office. services.

\section{Abstract}

The World Health Organization has set a global goal - reducing preventable mortality by $25 \%$. Violation of basic nutrition leads to the development of diseases, including food safety.

Objective: Learning experiences for monitoring food safety and developing recommendations for the population of the country of the Center of Sanitary and Epidemiological Expertise of the Medical Center of the Presidential

Material and methods: For 10 years (2007-2017) were used methods of statistical analysis of laboratory, which studies food products; content analysis of the legislative and regulatory system of quality management of public health

Results: The capabilities of material and technological analysis indicates that the laboratory of the Center for Sanitary and Epidemiological Expertise of the Medical Center of the Presidential Affairs Office can conduct analysis on the safety of the external environment (air, water, food) in an expanded range that meet the criteria of the international the ILAC system.

Conclusion: The Center for Sanitary and Epidemiological Expertise of the Medical Center of the Presidential Affairs Office is a model of organization and quality of food safety management, which is the basis of main chronic noncommunicable and infectious diseases.

Key words: food production monitoring and management, food safety, public health indicators related to nutrition

\section{ХАЛЫҚТЫН ДЕНСАУЛЫҚ КӨРСЕТКІШТЕРІН АРТТЫРУДАҒЫ ДЕНСАУЛЫҚ САҚТАУ ЖУЙЕСІНІН РӨЛІ}

Киясов Е.А., Сарыбаева Г.К., Хайдарова Т.С.

Саясат және денсаулық сақтауды ұйымдастыру кафедрасы, Әл-Фараби атындағы Қазақ ұлттық университеті, Алматы, Қазақстан Республикасы

\section{ТҰЖЫРЫМДАМА}

Бүкіләлемдік денсаулық сақтау ұйымының алдына қойған жаһандық мақсаты - алдын алуға болатын өлім-жітім көрсеткішін 25\% төмендету. Дұрыс тамақтанудың негіздері, оның ішінде азық-түліктің қауіпсіздігі бұзылғанда көптеген аурулардың дамитыны белгілі.

Мақсаты: Тамақ өнімдерінің қауіпсіздігі мен еліміздің тұрғындары үшін ұсынымдарды әзірлеу бойынша жүргізілген мониторинг нәтижесінде Президенті Іс Басқармасы Медициналық орталығының «Санитарлық-эпидемиологиялық сараптама орталығы» РМк (бұдан әрі - ҚР ПІБ МО «СЭСО» РМК) сараптама орталығының тәжірибесін зерттеу.

Әдістері: Жұмыс барысында тамақ өнімдерін зертханалық тексерудің 10 жылғы статистикалық талдау әдістері, қоғамдық денсаулық сақтау қызметінің сапасын басқару жүйесінің заңды нормативті контент анализі пайдаланылған (2007-2017жж);

Нәтижесі: Зертхананың материалдық-техникалық және технологиялық мүмкіндіктері ҚР ПІБ МО «Санитарлық-эпидемиологиялық сараптама орталығы» РMK-нің ILAC халықаралық жүйесінің критерийлеріне сәйкес келетін зертханалық тесерулердің кеңейтілген спектрі бойынша сыртқы орта (ауа, су, тамақ өнімдері) қауіпсіздігі бойынша тексерулер жүргізе алатындығын дәлелдейді.

Қорытынды: ҚР ПІБ МО «СЭСО» РМК тамақ өнімдерінің сапасын басқару және ұйымдастырудың моделі болып табылады, ал ол дегеніміз созылмалы инфекциялық және инфекциялық емес аурулардың алдын алудың негізі болып табылады.

Негізгі сөздер: тамақ өнімдерінің сапасын басқару мен мониторинг жүргізу, тамақ өнімдерінің қауіпсіздігі, тамақтанумен байланысты қоғамдық денсаулық көрсеткіштері 
РОЛЬ ОБЩЕСТВЕННОЙ СИСТЕМЫ ЗДРАВООХРАНЕНИЯ В УЛУЧШЕНИИ ПОКАЗАТЕЛЕЙ ЗДОРОВЬЯ НАСЕЛЕНИЯ

Киясов Е.А., Сарыбаева Г.К., Хайдарова Т.С.

Кафедра политики и организации здравоохранения, Казахский Национальный Университет имени Аль-Фараби, Алматы, Республика Казахстан

PEЗЮME

Всемирная Организация Здравоохранения определила глобальную цель - снижение предотвратимой смертности на $25 \%$. При нарушении основ здорового питания, в том числе безопасности питания, развиваются множество заболеваний.

Цель: Изучение опыта центра экспертизы РГП «Центр санитарно-эпидемиологической экспертизы» Медицинского центра Управления делами Президента (РГП «ЦСЭЭ» МЦ УДП РК ) по проведению мониторинга безопасности пищевых продуктов и разработке рекомендаций для населения страны.

Методы: В работе использованы методы статистического анализа лабораторных исследований по пищевой продукции за 10 лет (2007-2017гг); контент-анализа законодательно-нормативной системы управления качеством деятельности служб общественного здоровья.

Результаты: Анализ материально-технических и технологических возможностей лаборатории свидетельствует, что Центр санитарноэпидемиологической экспертизы РГП «ЦСЭЭ» МЦ УДП РК может проводить исследования по безопасности внешней среды (воздуха, воды, пищевых продуктов) по расширенному спектру лабораторных исследований, которые соответствуют критериям международной системы ILAC.

Заключение: РГП «ЦСЭЭ» МЦ УДП РК является моделью организации и управления качеством безопасности пищевой продукции, что является основой предупреждения хронических неинфекционных и инфекционных заболеваний.

Ключевые слова: мониторинг и управление качеством пищевой продукции, безопасность продуктов питания, показатели общественного здоровья, связанные с питанием

\section{Введение}

Смертность от хронических неинфекционных заболеваний (ХНИЗ) является ведущей причиной смертности во всем мире, около четверти случаев смерти это преждевременная смертность, и происходит в возрасте до 60 лет. В 2012 году ВО3 определила глобальную цель снижение предотвратимой смертности от ХНИЗ на 25\% [1].

В рамках Государственной программы развития Здравоохранения Республики Казахстан «Денсаулык» (20162019гг) определена цель - укрепление здоровья населения, что означает внедрение первичной профилактики ХНИЗ, т.е. проведение межсекторальных программ по созданию благоприятных для здоровья условий внешней среды, и принципов здорового питания [2]. Анализ показателей общественного здоровья населения Казахстана за 2016 -2017 годы показал, что не отмечается значительной динамики в снижении общей смертности, смертности от онкологических болезней, смертности от болезней системы кровообращения (БСК). Так, смертность от БСК в 2017 году составила 186,25 на 100000 населения, в 2016 она была 181,55 на 100000 населения. Опыт стран ОЭСР показал, что большинство ХНИЗ и преждевременная смертность от них являются предотвратимыми [3]. На лечение ХНИЗ по данным Министерства здравоохранения Республики Казахстан расходуется около 90\% средств бюджетных средств на здравоохранения, тогда как на профилактику этих заболеваний расходуется гораздо меньше. Так, в общем объеме финансовых средств на 2017 год (1 038807 тысяч тенге) только 5,47\%, или 56865 тыс. тенге были потрачены на профилактику[4]. Питание является одним из ведущих факторов здоровья населения, при нарушении основ здорового питания возникает около $60 \%$ заболеваний, в том числе и ХНИЗ [5].

В рамках ГПРЗ «Денсаулык» на базе ранее функционировавшей санитарно-эпидемиологической службы был создан Комитет общественного здравоохранения (КООЗ) при Министерстве здравоохранения Республики Казахстан и его филиалы по регионам, Департаменты Общественного здоровья, для проведения профилактики и укрепления здоровья населения и проведения межсекторальных программ по управлению немедицинскими факторами риска. Но следует отметить, что опыт стран по межсекторальной работе мало изучен, и в Казахстане нет единого плана для проведения межсекторальных программ по первичной профилактике факторов риска развития ХНИЗ. Общественное здравоохранение в странах ОЭСР получило развитие еще в 20-ом столетии, и является базовой составляющей любой системы здравоохранения. По данным научной литературы первичная профилактика ХНИЗ в странах ОЭСР достигла значительных положительных результатов. Например, в Финляндии снижение смертности от БСК на 75\% произошло за счет межсекторальных мер по внедрению приципов здорового питания, снижения табакокурения [6].

В связи с вышеизложенным имеется теоретическая и практическая значимость анализа опыта стран ОЭСР по организации деятельности систем общественного здравоохранения по проведению укрепления общественного здоровья населения, в том числе в целях обеспечения безопасности питания.

\section{Цель}

Провести анализ деятельности РГП «Центр санитарноэпидемиологической экспертизы» Медицинского центра Управления делами Президента по проведению мониторинга безопасности пищевых продуктов и разработать рекомендации по обеспечению контроля безопасности питания как одной из задач системы общественного здравоохранения Республики Казахстан.

\section{Материал и методы}

В работе использованы методы статистического анализа, контент-анализ законодательно-нормативных документов, сравнительный анализ показателей общественного здоровья по РК за 2016-2017 годы. Изучена законодательно-нормативная система по охране здоровья населения и по системе организации и проведения профилактики ХНИЗ в РК и в странах ОЭСР, документы ВО3 по данному вопросу, также документы по стандартизации и аккредитации медицинских и лабораторной службы СЭС, по системе менеджмента качества на основе международного стандарта серии ИСО 9001-2015 [7-8]. Проведено исследование деятельности РГП «ЦСЭ» МЦ УДП РК на основе анализа аккредитации, системы менеджмента качества, документированных процедур РГП «ЦСЭЭ» МЦ УДП РК по мониторингу качества пищевой продукции. Изучены основы структуры процесса мониторинга безопасности пищевой продукции, материально-технического оснащения лаборатории 
«ЦСЭЭ» МЦ УДП РК. В данной работе приведен анализ результатов деятельности ЦСЭ по контролю - пищевых продуктов за последние 10 лет (с 2010 г по 2018 год), до и после внедрения системы менеджмента качества и внедрения ИСО 9001-2009, проведения аккредитации лаборатории ЦСЭЭ МЦ УДП РК.

\section{Результаты}

По данным проведенного анализа материальнотехнической базы «ЦСЭЭ» МЦ УДП РК отмечена высокая технологическая оснащенность и большие возможности по достоверности лабораторной диагностики безопасности продуктов питания. В 2014 и в 2017 годах учреждение прошло аккредитацию международными оценщиками Национального Центра Аккредитации Республики Казахстан в соответствий с требованиями международного стандарта СТ РК ИСО/МЭК 17025-2007. На основании сертификации лаборатория получила Совмещенный международный Знак ILAK MRA №03-46/36. В практической деятельности по мониторингу проб пищевых продуктов лаборатория проводит разработку предупреждающих и корректирующих действий по управлению рисками с 2014 года, поэтому отмечается уменьшение процента несоответствующих исследований. В Таблице 1 приведены статистические данные по мониторингу показателей анализа и контроля пищевых продуктов.

Таблица 1 Процент исследований несоответствующих требованиям ГОСТ по видам продуктов питания за период с 2006 по 2017 годы

\begin{tabular}{|c|c|c|c|c|c|c|c|c|c|c|c|c|}
\hline \multirow{2}{*}{ Наименование } & \multicolumn{12}{|c|}{ \% несоответствующих исследований } \\
\hline & 2006 & 2007 & 2008 & 2009 & 2010 & 2011 & 2012 & 2013 & 2014 & 2015 & 2016 & 2017 \\
\hline $\begin{array}{c}\text { Исследовано проб всего, } \\
\text { в том числе: }\end{array}$ & 2,5 & 2,0 & 1,3 & 1,5 & 1,2 & 0,7 & 1,0 & 1,6 & 1,2 & 0,7 & 1,1 & 0,9 \\
\hline Мясо, мясопродукты, птица, яйца & 4,5 & 2,1 & 1,6 & 1,2 & 2,3 & 0,4 & 1,0 & 2,2 & 1,5 & 0,8 & 0,9 & 1,0 \\
\hline Молоко и молочные продукты & 2,8 & 3,4 & 2,0 & 1,7 & 1,2 & 0,7 & 0,6 & 1,1 & 1,3 & 1,0 & 1,1 & 0,7 \\
\hline Рыба, прод. рыбного промысла & 5,4 & 6,5 & 3,1 & 2,6 & 2,2 & 2,8 & 6,3 & 5,3 & 2,9 & 1,6 & 2,0 & 2,3 \\
\hline $\begin{array}{c}\text { Зерно,крупа и мукомольные } \\
\text { изделия, хлеб и хлебобулочные } \\
\text { изделия }\end{array}$ & 2,1 & 0,4 & 0,2 & 0,5 & 0,2 & 0,1 & 0,0 & 0,2 & 0,2 & 0,0 & 0,1 & 0,2 \\
\hline $\begin{array}{c}\text { Сахар, кондитерные изделия, } \\
\text { мед }\end{array}$ & 1,8 & 0,7 & 0,0 & 0,3 & 0,5 & 0,5 & 0,5 & 1,2 & 0,3 & 0,0 & 0,4 & 0,6 \\
\hline Плоды, овощи & 1,5 & 0,8 & 0,6 & 1,4 & 2,6 & 1,5 & 1,1 & 2,3 & 1,8 & 1,8 & 2,2 & 1,5 \\
\hline $\begin{array}{c}\text { Напитки безалкогольные, вода } \\
\text { минералная и бутылизирован- } \\
\text { ная }\end{array}$ & 1,0 & 0,4 & 0,0 & 0,4 & 0,0 & 0,2 & 0,2 & 0,0 & 0,7 & 0,0 & 0,0 & 0,1 \\
\hline Напитки спиртные & 2,2 & 4,3 & 0,3 & 3,0 & 1,3 & 0,8 & 1,5 & 2,0 & 1,1 & 0,7 & 0,5 & 0,2 \\
\hline Консервы & 2,6 & 2,6 & 2,6 & 0,6 & 1,6 & 0,4 & 0,3 & 2,4 & 2,1 & 0,5 & 1,0 & 1,5 \\
\hline $\begin{array}{c}\text { Прочее сырье и продукты } \\
\text { питания }\end{array}$ & 3,8 & 1,0 & 2,6 & 0,8 & 0,7 & 0,5 & 1,1 & 1,2 & 0,3 & 0,2 & 0,3 & 0,1 \\
\hline
\end{tabular}

В таблице отражен процент несоответствия пищевых продуктов требованиям ГОСТ по показателям органолептики. По видам пищевых продуктов показано значительное снижение показателей несоответствия. В целом установление наличия в пищевых продуктах патогенной флоры снижалось ежегодно, как это показано на Рисунке 1.

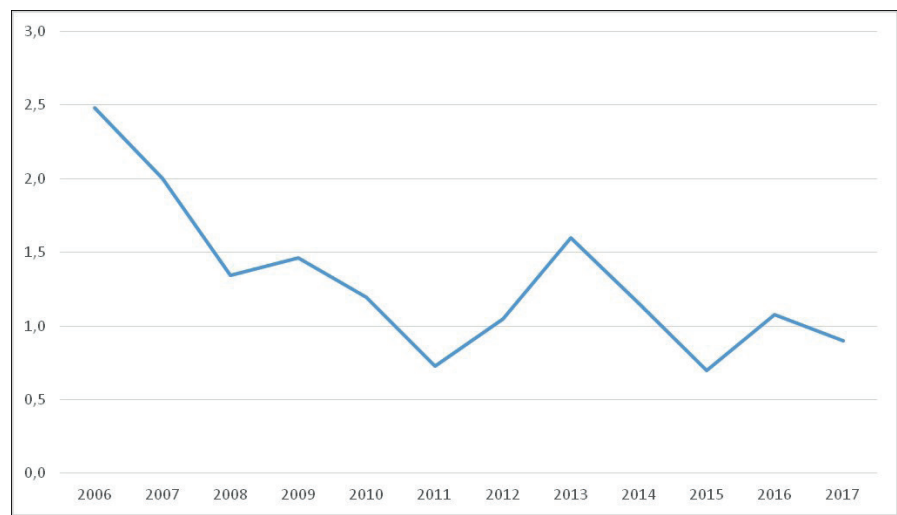

Рисунок 1 - Мониторинг несоответствия пищевых продуктов требованиям ГОСТ за период с 2006 по 2017 годы.

Journal of Clinical Medicine of Kazakhstan: Volume 2, Number 48, Issue 2018

\section{Обсуждение}

Проведение первичной профилактики, т.е. снижение или устранение влияния внешних факторов риска, и создание благоприятных условий для жизнедеятельности населения, является основой любой развитой системы общественного здравоохранения. В соответствии со статьей 153 Кодекса РК «О здоровье народа и системе здравоохранения» первичная профилактика заболеваний заключается в обеспечении здоровой внешней среды для жизнедеятельности человека, т.е это - чистый воздух, чистая вода и чистые продукты питания [9]. Вклад профилактических мероприятий составляет 55\%, а лечебных - 37\% в снижении преждевременной смертности населения от ХНИЗ, поэтому значение первичной профилактики возрастает в современный период развития здравоохранения РК [10]. В соответствии с международным стандартом «Codex Alimentarius» в целях безопасности питания для здоровья населения вся цепочка пищевой индустрии - от фермы до стола (выращивание, хранение, транспортировка, изготовление и продажа) - должна быть охвачена стандартизацией, сертификацией и мониторингом [11]. На каждом этапе пищевой цепочки должен быть 
мониторинг качества продуктов питания с применением современных методов выявления и контроля безопасности пищевых продуктов[12]. Система Общественного здравоохранения, основной целью которого является предупреждение развития заболеваний, в Казахстане только создана, поэтому изучение опыта РГП «ЦСЭЭ» МЦ УДП РК по обеспечению чистоты и безопасности пищевой продукции, является важным для профилактики заболеваний, снижения смертности населения и увеличения продолжительности жизни граждан РК.

\section{Выводы}

1. Получение сертификатов по системе менеджмента качества серии ИСО 9001-2015, сертификатов международной системы ILAC по лабораторной диагностике безопасности пищевых продуктов и других факторов внешней среды повысило качество лабораторной диагностики пищевых продуктов с показателя 2012 г по 2017 г.

2. Центр санитарно-эпидемиологической экспертизы РГП «ЦСЭЭ» МЦ УДП РК имеет международные сертификаты по расширенному спектру лабораторных исследований и практически может проводить исследования по безопасности внешней среды (воздуха, воды, пищевых продуктов) во всех странах мира, входящих состав международной системы ILAC. Деятельность центра экспертизы РГП «ЦСЭЭ» МЦ УДП РК можно считать Моделью организации Служб общественного здравоохранения по мониторингу безопасности пищевой продукции для населения РК.

Disclosures: There is no conflict of interest for all authors.

\section{Список литературы}

1. Global action plan for the prevention and control of NCDs 2013-2020, English, ISBN: 978924 150623 6.-2013.-55p.

2. State program for the development of healthcare of the Republic of Kazakhstan "Densaulyk", 2016-2019. Retrieved from http:// www.mz.gov.kz/ru

3. Health 2020: the European policy for health and well-being. Retrieved from http://www.euro.who.int/en/health-topics/healthpolicy/health-2020-the-european-policy-for-health-and-well-being/about-health-2020

4. Report of the Deputy Minister of Healthcare of the Republic of Kazakhstan, V.Tsoy, Ministry of Healthcare of the Republic of Kazakhstan, 2017. Retrieved from http://www.rcrz.kz/index.php/ru/2017-03-12-10-50-44/smi-o-nas/210-news-10042017-3

5. Sharmanov T.Sh. Health and disease. 2012; 4 (106)

6. P. Puska, E. Vartiainen, T. Laatikainen. ISBN 978-952-245-435-5/ Helsinki Universtity Edition. 2011

7. International Standard, Quality Management System ISO 9001-2015

8. International Standard, ST RK ISO/MEK 17025-2007.

9. Code of the Republic of Kazakhstan «On Public Health and Healthcare System" (September 18, 2009 No193-IV Law of the RK).

10. Nevzorova V.A., Brodskaya T.A., MArtynenko I.M. Prevention of main chronic non-infectious diseases in the population mortality structure (part 1). Vladivostok: Meditsina DV; 2017. 140p.

11. State program for the healthcare development «Salamatty Kazakhstan”, 2011-2015. Retrieved from http://www.mz.gov.kz/ru

12. Reports of the Republican State Enterprise "Center of Sanitary-Epidemiological Expertise" of the Medical Centre of President's Affairs Administration of the Republic of Kazakhstan for 2010-2017. Retrieved from http://ru.mcudprk.kz/index.php/o-centre/ podvedomstvennye-organizatsii-2?id=681

How to cite this article: Yerlan Kiyassov, Gulya Sarybaeva, Togzhan Khaidarova. The role of the public health system in improving health indicators of population [in Russian]. J Clin Med Kaz. 2018; 2(48):59-62 